\title{
O062. Post ambulatory surgery headache in patients affected from primary headaches: a comparison with the general population
}

\author{
Giovanni F Manfredi ${ }^{*}$, Francesco De Cesaris ${ }^{2}$, Eugenia Tomas Roldan ${ }^{3}$ \\ From Abstracts from the 1st Joint ANIRCEF-SISC Congress \\ Rome, Italy. 29-31 October 2015
}

\section{Background}

Primary headaches, such as tension-type headache and migraine, are very common. Migraine is one of the most weakening diseases, especially in women [1]. Ambulatory surgery consists in performing some surgical procedures, in selected patients, with discharge from the hospital the same working day [2]. After discharge, some complications may occur at home, above all, pain, nausea, vomiting and headache. We detected the predominance of headache at home in women affected from primary headaches compared to the general population, and its correlation with both anesthesia, the medications usually taken for headache and the drugs given during the intraoperative period.

\section{Methods}

Previously we analyzed data collected within an interval of four months, regarding 1,479 patients (Group A) whom had undergone ambulatory surgery and discharged following the criteria of Post anesthetic discharge score system (PADSS) [3]. At a later stage, we decided to study, in the same way, 64 patients with history of primary headache (Group B - Table 1), treated with a different type of anesthesia (Table 2). Nurses questioned all the patients, during two phone calls at home, both in the evening and in the morning following their discharge from the hospital, concerning the presence of headache and its intensity measured with the Numerical Rating Scale (NRS).

We also analyzed data about the personal medications taken for headache, the type of anesthesia, the drugs received during operations for nausea and vomiting

\footnotetext{
* Correspondence: gianfranco.manfredi@ieo.it

${ }^{1}$ Centro Day Surgery, Istituto Europeo di Oncologia IRCCS, Milan, Italy

Full list of author information is available at the end of the article
}

Table 1

\begin{tabular}{ll}
\hline Features & Patients \\
Female & 64 \\
Age $48.2( \pm 8)$ & \\
Type of Headache $(\mathrm{HCD}-3)[4]$ & 6 \\
Tension-type headache & 5 \\
Migraine with aura & 52 \\
Migraine without aura & 1 \\
Cluster headache & \\
Symptomatic Medications & 15 \\
Triptans & 23 \\
NSAIDs & 8 \\
Acetaminophen & 7 \\
Combinations & 1 \\
O2 therapy & 10 \\
None & \\
Preventive Medications & 8 \\
B-blockers & 5 \\
Amitriptyline & 3 \\
Topiramate & 6 \\
Vitamins and Supplements & 42 \\
None & \\
\hline
\end{tabular}

such as ondansetron and/or dexamethasone [5] and for postoperative pain, such as acetaminophen, tramadol or ketorolac, individually or combined.

\section{Results}

One hundred and ninety-six patients (13.27\%) of Group A and 11 patients (17.19\%) of Group B had been suffering from headache at home (Table 3). In Group B, no correlation was shown with usual assumption of headache treatments, the technique of anesthesia, the administration of either prophylaxis for nausea and vomiting (OR: 1.006; 50\% CI: 0.52-1.93), or analgesic drugs for 
Table 2

\begin{tabular}{ll}
\hline Anesthesia & N. \\
\hline Local & 2 \\
Sedation & 2 \\
Local + Sedation (MAC) & 6 \\
General & 54 \\
\hline
\end{tabular}

Table 3

\begin{tabular}{lll}
\hline & Group A & Group B \\
Patients n. & 1479 & 64 \\
Headache $\mathbf{n .}$ & 196 & 11 \\
$\boldsymbol{P}$ & 0.132 & 0.171 \\
$\mathbf{9 5 \%}$ IC & $0.11-0.15$ & $0.08-0.28$ \\
& (OR: $1.42,50 \%$ IC: $1.06-1.9)$ \\
NRS 1-3 & $63 \%$ & $35 \%$ \\
NRS 4-6 & $29 \%$ & $50 \%$ \\
NRS 7-10 & $8 \%$ & $15 \%$ \\
\hline
\end{tabular}

the treatment of the postoperative pain (OR: $1.77 ; 50 \%$ CI: $0.54-7.42)$. Nevertheless, we noted a higher incidence of headache after the administration of acetaminophen alone (OR: 4.32, 50\% IC: 1.36-17.15) but lower incidence with ketorolac both alone or in combination (OR: $0.48,50 \%$ IC: $0.24-1.00$ ), and with dexamethasone (OR: $0.125,50 \%$ IC: $0.02-0.49$ ).

\section{Conclusions}

The study showed that headache is a very frequent complication at home, after ambulatory surgery. A higher incidence of headache in the patients already affected from primary headaches was observed. Few correlations, only with some single drug administered during the intraoperative period, were found.

Written informed consent to publication was obtained from the patient(s).

\section{Authors' details}

${ }^{1}$ Centro Day Surgery, Istituto Europeo di Oncologia IRCCS, Milan, Italy.

${ }^{2}$ Centro Cefalee, Dip. Scienze della Salute, Università degli Studi di Firenze, Florence, Italy. ${ }^{3}$ Unità Ginecologia Preventiva, Istituto Europeo di Oncologia IRCCS, Milan, Italy.

Published: 28 September 2015

\section{References}

1. Benemei S, Nicoletti P, Capone JG, De Cesaris F, Geppetti P: Migraine. Handb Exp Pharmacol 2009, 194:75-89.

2. The Association of Anaesthetists of Great Britain \& Ireland, The British Association of Day Surgery, et al: Day case and short stay surgery: 2. Anaesthesia 2011, 66:417-434

3. Marshall Sl, Chung F: Discharge criteria and complications after ambulatory surgery. Anesth Analg 1999, 88:508-17.

4. Headache Classification Committee of the International Headache Society (IHS): The International Classification of Headache Disorders, 3rd edition (beta version). Cephalalgia 2013, 33:629-808.
5. Bano F, Zafar S, Aftab S, Haider S: Dexamethasone plus ondansetron for prevention of postoperative nausea and vomiting in patients undergoing laparoscopic cholecystectomy: a comparison with dexamethasone alone. J Coll Physicians Surg Pak 2008, 18(5):265-9.

doi:10.1186/1129-2377-16-S1-A123

Cite this article as: Manfredi et al:: 0062. Post ambulatory surgery headache in patients affected from primary headaches: a comparison with the general population. The Journal of Headache and Pain 201516 (Suppl 1):A123.

\section{Submit your manuscript to a SpringerOpen ${ }^{\mathcal{O}}$ journal and benefit from:}

- Convenient online submission

- Rigorous peer review

- Immediate publication on acceptance

- Open access: articles freely available online

- High visibility within the field

- Retaining the copyright to your article

Submit your next manuscript at $>$ springeropen.com 